\title{
Interim Evaluation of the Secondary 2 Program of Project P.A.T.H.S.: Insights Based on the Experimental Implementation Phase
}

\author{
Daniel T.L. Shek ${ }^{1,2,3, *}$, Rachel C.F. Sun ${ }^{3}$, and Andrew M.H. Siu ${ }^{4}$ \\ ${ }^{1}$ Quality of Life Centre, Hong Kong Institute of Asia-Pacific Studies, The Chinese \\ University of Hong Kong; ${ }^{2}$ Kiang Wu Nursing College of Macau; ${ }^{3}$ Social Welfare \\ Practice and Research Centre, The Chinese University of Hong Kong; ${ }^{4}$ Department \\ of Rehabilitation Science, The Hong Kong Polytechnic University \\ E-mail: danielshek@cuhk.edu.hk
}

Received October 15, 2007; Revised November 26, 2007; Accepted November 27, 2007; Published January 14, 2008

An interim evaluation was conducted to understand the implementation quality of the Tier 1 Program (Secondary 2 Curriculum) of the Project P.A.T.H.S. (Positive Adolescent Training through Holistic Social Programs) in the Experimental Implementation Phase. Twenty-five schools were randomly selected to participate in personal and/or telephone interviews to provide information on the implementation details of the program and perceived attributes of the worker-support scheme ("Co-Walker Scheme"). Results showed that a majority of the workers perceived that the students had positive responses to the program and the program was helpful to the students. They also identified several good aspects in the program and the Co-Walker Scheme, albeit expressing some negative comments on the program design and difficulties in the implementation process. In conjunction with other findings reported previously, the present findings suggest that the Tier 1 Program is well received by different stakeholders and it promotes the positive development of secondary school students in Hong Kong.

KEYWORDS: interim evaluation, positive youth development, Chinese adolescents

\section{INTRODUCTION}

Positive Adolescent Training through Holistic Social Programmes (P.A.T.H.S.) is a positive youth development program financially supported by The Hong Kong Jockey Club Charities Trust to promote holistic adolescent development in Hong Kong[1,2]. There are two implementation phases in this project Experimental Implementation Phase (2005/06 to 2007/08 school years) and Full Implementation Phase (2006/07 to 2009/2010 school years). For the Tier 1 Program, the research team developed a set of curriculum manuals[1,2,3] that includes materials based on 15 positive youth development constructs identified from the existing successful positive youth development programs[4], and had taken reference with relevant research findings and existing programs in both local and foreign contexts. To provide 
support to colleagues who implement the Tier 1 Program, the research team had launched a "Co-Walker Scheme” since December 2006, which aimed to provide ongoing support and guidance to the participating schools.

Although papers documenting the positive program effects of the Tier 1 Program of P.A.T.H.S. have been published[5,6,7,8,9,10,11,12,13,14,15,16,17], they are limited to the Secondary 1 curriculum. As mentioned by Shek et al.[18], there are several developmental characteristics of Secondary 2 students. These include adjustment to puberty, cognitive maturation, rapid expansion of social circle, increased stress, encountering higher levels of social expectations, and gradual detachment from the family. Furthermore, they pointed out that compared with Secondary 1 students, Secondary 2 students have poorer psychological well-being and adaptation skills, and they perceived family functioning to be poorer and parental control to be looser. With such characteristics in Secondary 2 students, it is important to ask whether their reactions to positive youth development programs would be different from those of Secondary 1 students. Therefore, understanding the reactions of the students and the program implementers in the process is important.

Similar to the evaluation of the Secondary 1 Curriculum in the first year of the Experimental Implementation Phase[5] and Full Implementation Phase[6], an interim evaluation of the Secondary 2 Curriculum was carried out to examine the views of the workers regarding the implementation of the Tier 1 Program, based on a random sample of schools joining the second year of the Experimental Implementation Phase in the 2006/07 school year. As there are no empirical studies on process evaluation, it is argued that more work on process evaluation should be done[19,20,21,22].

\section{METHODS}

\section{Participants}

There were 49 schools that joined the Secondary 2 curriculum of the Project P.A.T.H.S. in the Experimental Implementation Phase in the 2006/07 academic year. Among these schools, 21 adopted the 20-h full program that involves 40 teaching units and 28 adopted the 10-h core program that involves 20 teaching units. Among these participating schools, 14 schools that joined the full program and 11 schools that joined the core program were randomly selected to participate in this study. In these selected schools, the instructors of the program (either school teachers or social workers) were invited to participate in faceto-face interviews on a voluntary basis during a school visit. If the respondents were not available for interviews during the school visit, they were invited to participate in telephone interviews or to complete self-administered questionnaires and return via e-mail or fax. Among these 25 schools, 15 took part in face-to-face interviews, six participated in telephone interviews, and four completed self-administered questionnaires. The respondents included 23 teachers and nine social workers. With reference to Principle 2 in the implementation of qualitative evaluation research proposed by Shek et al.[23], the number of schools that participated in this research can be regarded as respectable, as about half of the participating schools of the project in the second year of the Experimental Implementation Phase joined the interviews. Moreover, because the schools were randomly selected, the generalizability of the findings could be enhanced.

\section{Procedures}

The procedures for data collection are systematically described below, and this satisfied Principle 3 in the procedures of a qualitative research[23]. The data collection was conducted between January and April 2007. As the Experimental Implementation Phase took place from September 2006 to August 2007, January to April 2007 can be regarded as the midpoint of the implementation process. While the presence 
of interviewers may affect the responses of the respondents (e.g., social desirability effect) in face-to-face interviews, it is unlikely to happen because the interviewers were the co-walkers of the interviewed schools with which a friendly rapport and mutual trust had been built. Also, the major advantage of faceto-face interviews is having the opportunity to clarify any doubts instantly. On the other hand, while telephone interviews and self-administered questionnaires have the problems of psychological distance and inability to observe the nonverbal cues of the respondents, their major advantage is efficiency in collecting the data within the time limit. In addition, follow-up calls could be arranged if there was a need to clarify the responses of the respondents. Therefore, these data collection methods have complemented each other.

A self-constructed semi-structured interview guide with five closed-ended questions and seven openended questions was used to collect information on the program implementation process. The open-ended questions were:

- Question 1: What are the responses of the students to this program?

- Question 2: Do you think this program is beneficial to the students? If yes, what are the benefits?

- Question 3: What are the good aspects of the program?

- Question 4: Which areas of the program require improvement?

- Question 5: Have you encountered any difficulties during the program implementation process? If yes, what problems have you encountered?

- Question 6: What are your perceptions of the "Co-Walker Scheme”?

- Question 7: Do you have other opinions?

Informed consent was obtained from the respondents and they participated in the study in a voluntary manner. The interviews were conducted by six co-walkers, who were a colleague having a doctoral degree and five registered social workers with substantial working experience. After each interview, the interviewers were required to fill in the questionnaires. The completed questionnaires were then transcribed and analyzed.

\section{Data Analyses}

For the quantitative data (close-ended questions), frequencies and percentages of responses were calculated. The qualitative data (open-ended questions) were analyzed using general qualitative analyses techniques[24]. There were three steps in the process. First, relevant raw codes were developed for words, phrases, and/or sentences that formed meaningful units at the raw responses level. Second, the codes were further combined to reflect higher-order attributes at the category of codes level. Third, the categories of codes were further analyzed to reveal the broader themes at the thematic level. For example, the response to "involved in video watching" at the raw response level could be subsumed under the category of "high student involvement", which could be further subsumed under the broad theme of "positive responses" of the students to the program (see Table 2). Following the principles of qualitative analyses[23], the raw data and categorized data were kept by a systematic filing system in order to ensure that the findings are auditable.

The qualitative data were coded and categorized by two trained research assistants, of which one has a Bachelor Degree of Psychology and another has a Master Degree of Social Work, which were further checked by the second author. In the present analyses, as the researchers designed the program in the Project P.A.T.H.S., they were conscious of their own biases and expectation on the program to be effective. In addition, in order to minimize the possible biases involved, both intra- and inter-rater reliability on the coding was calculated. For intrarater reliability, a research assistant and the second author individually coded 20 randomly selected responses for each question. For inter-rater reliability, a research assistant with a Master Degree and another research assistant who is a registered social worker, who was not involved in the data collection and analyses, coded 20 randomly selected responses for each question without knowing the original codes given at the end of the scoring process with reference to the codes 
finalized by the first author. This met Principles 4-9 of conducting a qualitative study advocated by Shek et al.[23].

\section{RESULTS}

\section{Responses of the Students to the Program}

About $92 \%$ of the respondents reported that the students were involved and liked the program (Table 1) and most of the perceived student responses were positive (64.9\%) (Table 2). The intrarater agreement percentages were 100 and 100\%, and the inter-rater agreement percentages were 80 and 95\%, respectively, for responses reported in Table 2.

TABLE 1

Instructors' Ratings of the Secondary 2 Curriculum (N and Percentage)

1. Perceived degree of student involvement

\begin{tabular}{|c|c|c|c|c|c|c|}
\hline & Totally Not Involved & Not Involved & Involved & Totally Involved & No Response & Total \\
\hline $\mathrm{N}$ & 0 & 2 & 22 & 1 & 0 & 25 \\
\hline$\%$ & 8 & & & 92 & 0 & 100 \\
\hline
\end{tabular}

2. Perceived degree of students' liking of the Secondary 2 Curriculum

\begin{tabular}{cccccccc}
\hline & Strongly Dislike & Dislike & Like & Strongly Like & No Response & Total \\
\hline $\mathrm{N}$ & 0 & & 2 & 23 & 0 & 0 & 25 \\
\hline$\%$ & & & & 92 & 0 & 100 \\
\hline
\end{tabular}

3. Perceived degree of helpfulness of the Secondary 2 Curriculum

\begin{tabular}{ccccccccc}
\hline & Unhelpful & Not Very Helpful & Slightly Helpful & Helpful & Very Helpful & No Response & Total \\
\hline $\mathrm{N}$ & 0 & & 1 & 11 & 11 & 2 & 0 & 25 \\
\hline$\%$ & & 4 & & & 96 & & 0 & 100 \\
\hline
\end{tabular}

4. Perceived degree of workers' liking of the Secondary 2 Curriculum

\begin{tabular}{cccccccc}
\hline & Strongly Dislike & Dislike & Like & Strongly Like & No Response & Total \\
\hline $\mathrm{N}$ & 0 & & 0 & 15 & 3 & 7 & 25 \\
\hline$\%$ & 0 & & & 72 & 28 & 100 \\
\hline
\end{tabular}

5. Perceived degree of workers' overall satisfaction of the Secondary 2 Curriculum 


\begin{tabular}{ccccccccc}
\hline & $\begin{array}{c}\text { Very } \\
\text { Dissatisfied }\end{array}$ & Dissatisfied & $\begin{array}{c}\text { Slightly } \\
\text { Dissatisfied }\end{array}$ & $\begin{array}{c}\text { Slightly } \\
\text { Satisfied }\end{array}$ & Satisfied & $\begin{array}{c}\text { Very } \\
\text { Satisfied }\end{array}$ & $\begin{array}{c}\text { No } \\
\text { Response }\end{array}$ & Total \\
\hline $\mathrm{N}$ & 0 & 0 & 2 & 7 & 16 & 0 & 0 & 25 \\
\hline$\%$ & & 8 & & & 92 & & 0 & 100 \\
\hline
\end{tabular}

TABLE 2

Workers' Perceptions of the Responses of the Students to the Secondary 2 Curriculum

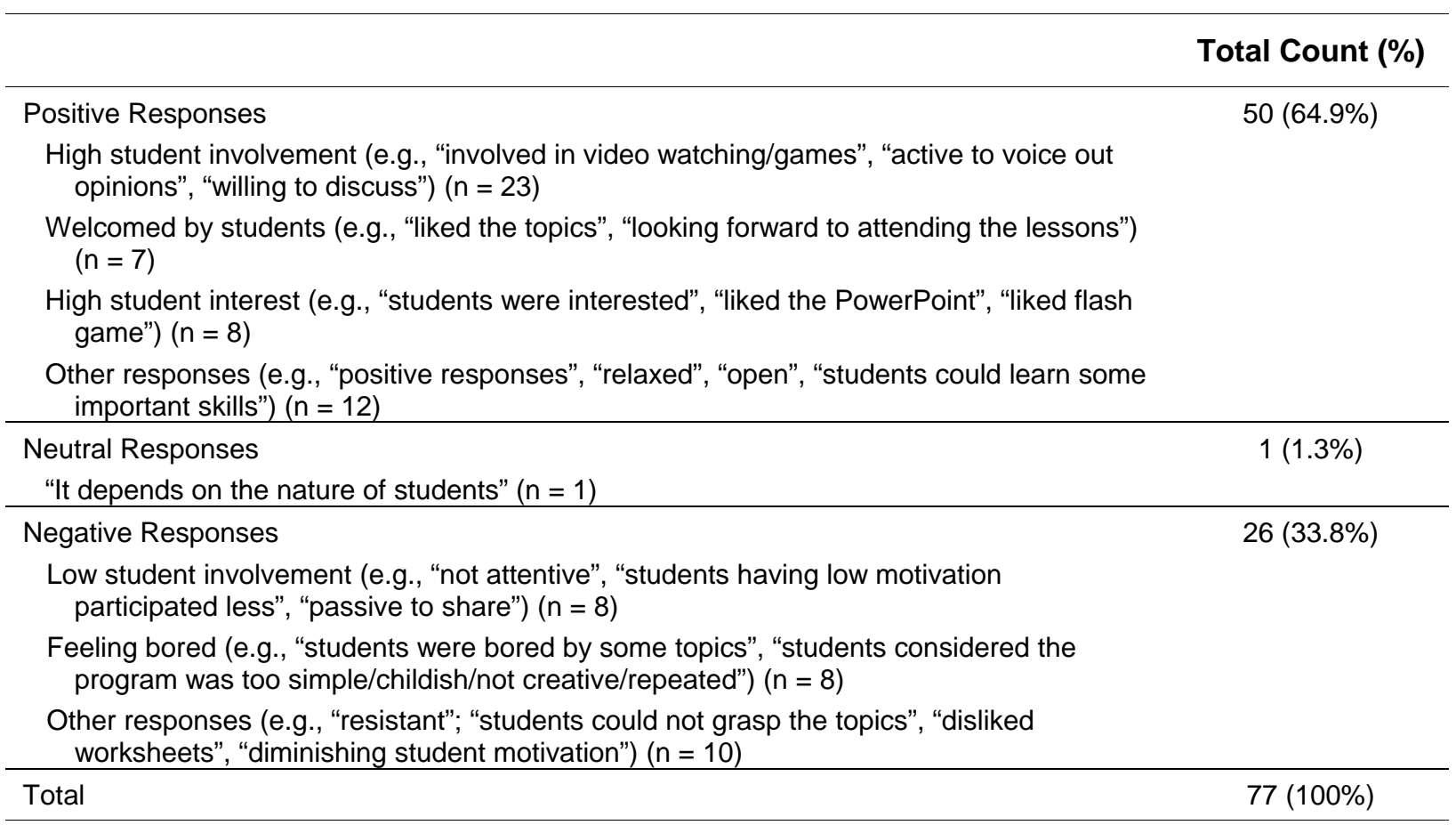

\section{Perceived Benefits of the Program to the Students}

About $96 \%$ of the respondents regarded the Tier 1 Program of the Secondary 2 Curriculum as helpful to the students (Table 1) and most of responses presented in Table 3 were positive in nature. The intrarater agreement percentages were 100 and $80 \%$, and the inter-rater agreement percentages were 85 and $90 \%$, respectively.

\section{Positive Aspects of the Program and Areas that Require Improvement}

As shown in Table 4, there were 72 meaningful units regarding the positive aspects of the program. The intrarater agreement percentages were 100 and 95\%, and the inter-rater agreement percentages were 95 and $90 \%$, respectively. On the other hand, there were 51 meaningful units concerning the aspects of the program requiring improvement (Table 5). About half of the responses indicated the "curriculum content and activity design" needed to be modified (51.0\%), while some responses suggested improving the "teaching manuals and resources" (17.6\%) and adjusting the "implementation time" (11.8\%). The intrarater agreement percentages were 100 and $100 \%$, and the inter-rater agreement percentages were 80 and $85 \%$, respectively. 


\section{Difficulties Encountered during Program Implementation}

As shown in Table 6, there were 44 meaningful units indicating the workers' perception of the difficulties encountered during program implementation. Among them, most of the responses were related to difficulties in "administration and coordination" (31.8\%), which was followed by the perceived difficulties in "time management" (13.6\%) and "heavy workload" (13.6\%), then in handling "students' responses" (11.4\%) and the "curriculum content and activity design" (9.1\%). The intrarater agreement percentages were 100 and 85\%, and the inter-rater agreement percentages were 90 and 85\%, respectively.

TABLE 3

Workers' Perceptions of the Benefits of the Secondary 2 Curriculum

\begin{tabular}{|c|c|}
\hline & Total Count (\%) \\
\hline Undecided & $8(17.8 \%)$ \\
\hline $\begin{array}{l}\text { Facilitating Students' Holistic Development } \\
\text { "The content is broad/related to daily life" }(n=4) \\
\text { "It facilitates students' growth/development" }(n=2)\end{array}$ & $6(13.3 \%)$ \\
\hline $\begin{array}{l}\text { Building Up Interpersonal Relationships } \\
\text { "Students learn how to choose/get along with friends" }(n=2) \\
\text { "It enables students to understand/get along with others" }(n=4) \\
\text { "It enables students to get along with their parents" }(n=1)\end{array}$ & $7(15.6 \%)$ \\
\hline $\begin{array}{l}\text { Strengthening Students' Behavioral and Cognitive Competence } \\
\text { "It enables students' thinking skills" }(n=5) \\
\text { "It enables students' problem-solving/goal-setting/presentation skills" }(n=3)\end{array}$ & $8(17.8 \%)$ \\
\hline $\begin{array}{l}\text { Enhancing Students' Self-Development } \\
\text { "It enables students to reflect on one's personality/values/developmental issues" }(n=6) \\
\text { "It enables students to have more self-understanding/self-growth" }(n=3)\end{array}$ & $9(20.0 \%)$ \\
\hline $\begin{array}{l}\text { Facilitating Students' Learning } \\
\text { "Students had improvement in Secondary 2, when compared with their Secondary 1" }(\mathrm{n}= \\
2 \text { ) } \\
\text { "Students could tell what they had learned from the lessons" }(\mathrm{n}=3) \\
\text { "It stimulates students' learning" }(\mathrm{n}=2)\end{array}$ & $7(15.6 \%)$ \\
\hline Total & 45 (100\%) \\
\hline
\end{tabular}

\section{Perceptions of the "Co-Walker Scheme"}

For the workers' perceptions of the "Co-Walker Scheme” (Table 7), about 60\% responses were positive and $37.5 \%$ were "none/no comment/undecided". The intrarater agreement percentages were 100 and 90\%, and the inter-rater agreement percentages were 100 and 100\%, respectively.

\section{Other Opinions of the Project}

About 72 and 92\% of the respondents showed that they liked the program and felt satisfied, respectively (Table 1). The responses to the open-ended question of other opinions of the project were shown in Table 8. The intrarater agreement percentages were 100 and $80 \%$, and the inter-rater agreement percentages were 85 and 95\%, respectively. 


\section{DISCUSSION}

Several phenomena could be highlighted from the present study. First, the respondents felt that most of the students had positive responses to the program, as shown in the findings reported in Tables 1-4. These findings are similar to the interim evaluation findings on the Tier 1 Program (Secondary 1 Curriculum) in the Full Implementation Phase (2006/07 school year)[6], and further supported the findings arising from the objective outcome evaluation[7,8], subjective outcome evaluation[9,10,11,12,13], qualitative evaluation based on student focus group[14] and students' weekly diaries[15], and process evaluation in

TABLE 4

Workers' Perceptions of the Positive Aspects of the Secondary 2 Curriculum

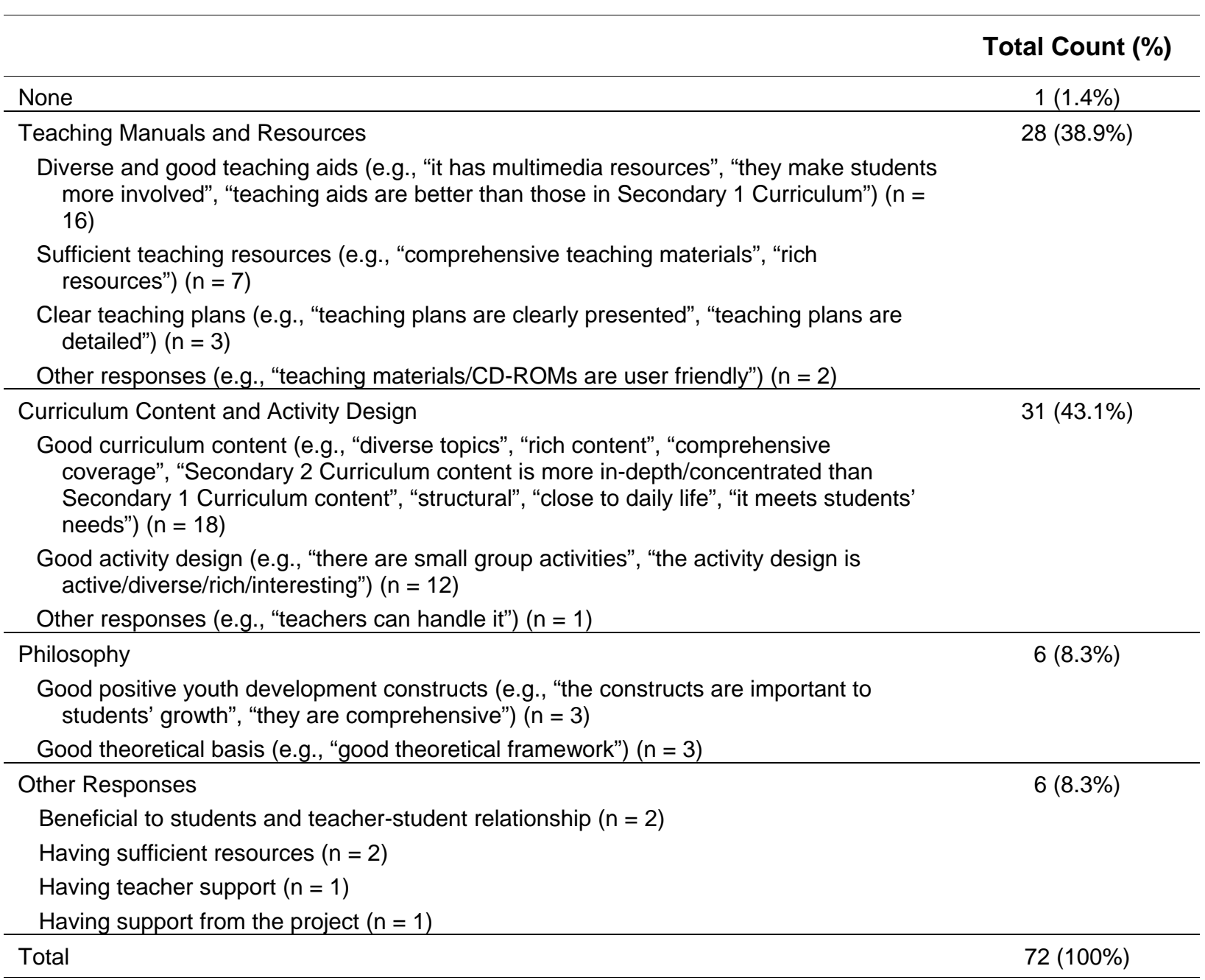

terms of observation[16] and interim evaluation[5] of the Secondary 1 Curriculum in the Experimental Implementation Phase (2005/06 school year) that both the students and workers had positive perceptions of the program, and the program was beneficial to the students.

Besides, the respondents also pointed out several aspects of the program that require improvement and difficulties encountered in the implementation process (Tables 5, 6, and 8). Similar to previous findings[5,6], about half of the responses referred to the curriculum content and activity design requiring modifications. As indicated in the previous papers[17,25], the experiential learning approach underlining 
the Tier 1 Program of Project P.A.T.H.S. requires the collaboration between teachers and students that may not be entirely consistent with the traditional Chinese way of education (emphasis on didactic learning) and authority figure of the teachers[26].

In addition, similar to previous findings[5,6], nearly one-third of the responses reported having difficulties in administration, and coordination and time management. Although it was the second year of program delivery in the Experimental Implementation Phase, it is possible that some schools deployed much manpower to run the Secondary 1 and 2 programs. Furthermore, for cases where the program was incorporated into the formal curriculum, assessment and covering the syllabus are stressors for the program implementers. Although there could be different interpretations of the above findings, these

TABLE 5

Workers' Perceptions of the Aspects of the Secondary 2 Curriculum that Require Improvement

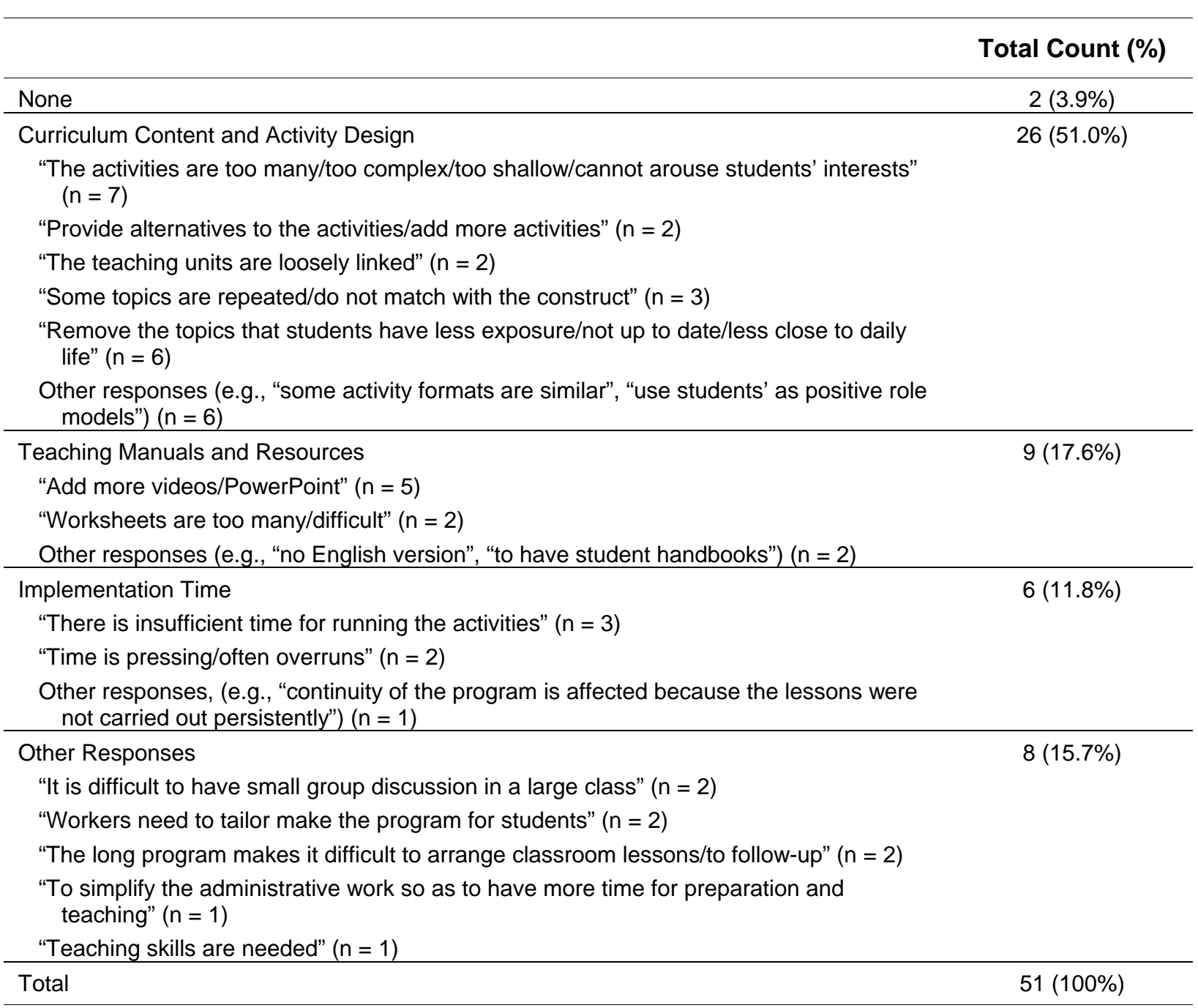

comments made by the respondents provide invaluable feedback on further improvement of the program, and the research team would seriously consider the comments collected and recorded. Also, it is noteworthy that the present findings provide an opportunity for the school or agency administrators and workers to reflect on how their administration and coordination, time management, teaching skills, and attitudes could be further improved. 
Regarding the "Co-Walker Scheme", as it had just been launched for 1-4 months at the time of data collection, it is understandable that about $38 \%$ of respondents had no comment or could not comment on it (Table 7). Nonetheless, a majority of the responses (60\%) indicated that the scheme was good and welcomed by the workers.

Following Principle 10 of conducting a qualitative study[23], three possible alternative explanations were put forward for the present findings - demand characteristics, selection bias, and ideological biases of the researchers. However, these explanations are not likely because (1) the respondents were encouraged to voice their views without restriction and negative voices were, in fact, heard; (2) the schools were randomly selected; and (3) several safeguards were used to reduce biases in the data collection and analysis process, such as multiple colleagues involved to provide checking for individual biases, as well as intra- and inter-rater reliability checks carried out to safeguard consistency in coding.

TABLE 6

Workers' Perceptions of the Difficulties Encountered in Secondary 2 Curriculum Implementation

Total Count (\%)

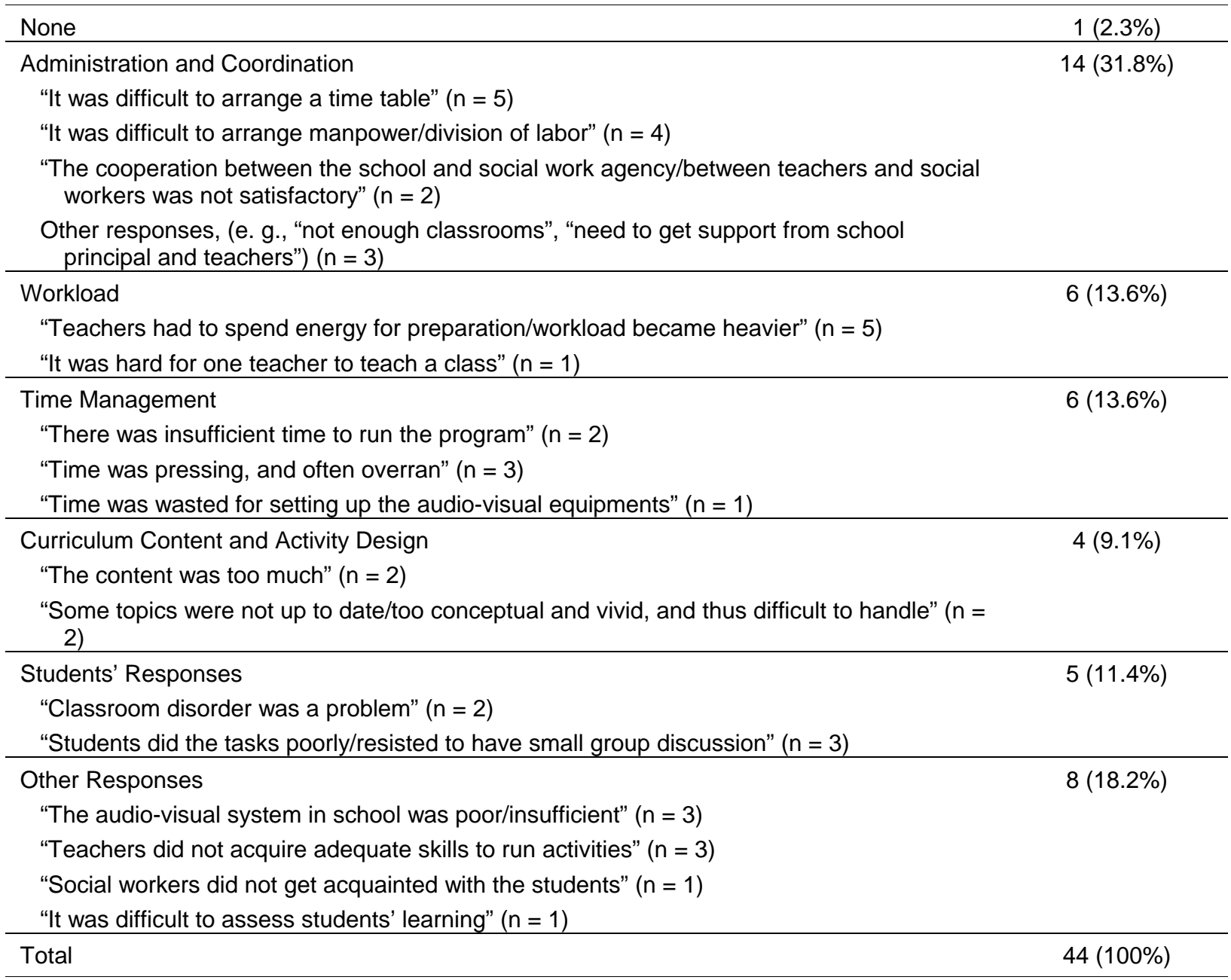

According to Principle 12 proposed by Shek et al.[23], several limitations of the study are described below. First, as each interview was brief and some data were collected through self-administrated 
TABLE 7

Workers' Perceptions of the "Co-Walker Scheme" (Secondary 2 Curriculum)

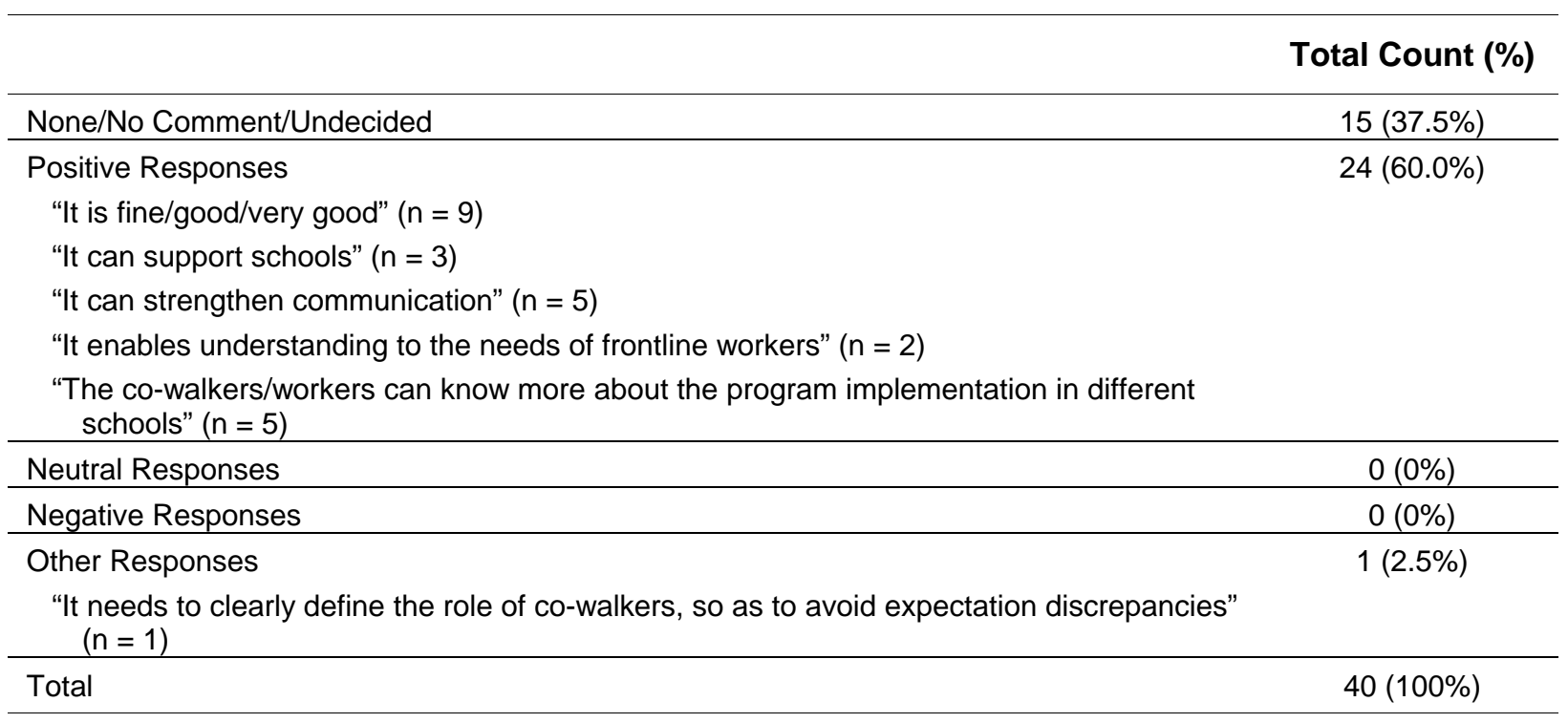

TABLE 8

Other Opinions of the Project (Secondary 2 Curriculum)

Total Count (\%)

\begin{tabular}{lc}
\hline None & $14(50.0 \%)$ \\
\hline Curriculum Content and Activity Design & $5(17.9 \%)$ \\
"Having too many worksheets" $(\mathrm{n}=1)$ & \\
"The curriculum content can be more challenging to students" $(\mathrm{n}=1)$ & $3(10.7 \%)$ \\
"Include more discussion/reflection/soundtracks and videos" $(\mathrm{n}=3)$ & \\
\hline School Administration and Co-ordination & \\
"If teachers are in charge of the program, it is hoped that the school can receive financial \\
$\quad$ support" $(\mathrm{n}=1)$
\end{tabular}

questionnaires, the researchers were not able to collect in-depth information and construct "thick descriptions". Therefore, in-depth individual or focus group interviews would be helpful to further 
understand the subjective experiences of the program implementers and participants. Second, this interim evaluation was a kind of process evaluation of a program with the program implementers only; therefore, another qualitative study that utilized students' weekly diaries to collect students' perceptions of the Secondary 2 Program was also conducted at the end of the program to further explore the program implementation quality. Despite these limitations, this study in the second year of the Experimental Implementation Phase provides interim evaluation findings that contribute to the Chinese literature on positive youth development programs. It also supports the positive attributes of the Project P.A.T.H.S. and its effectiveness in promoting holistic youth development among Chinese adolescents in Hong Kong. Based on the principle of triangulation[27], evaluation findings based on different methods, different data, and different sources of information generally provide evidence for the effectiveness of the Tier 1 Program of the P.A.T.H.S. Project.

\section{ACKNOWLEDGMENTS}

The preparation for this paper and the Project P.A.T.H.S. were financially supported by the Hong Kong Jockey Club Charities Trust.

\section{REFERENCES}

1. Shek, D.T.L. (2006) Construction of a positive youth development program in Hong Kong. Int. J. Adolesc. Med. Health 18(3), 299-302.

2. Shek, D.T.L. and Ma, H.K. (2006) Design of a positive youth development program in Hong Kong. Int. J. Adolesc. Med. Health 18(3), 315-327.

3. Shek, D.T.L., Ma, H.K., and Merrick, J., Eds. (2007) Positive Youth Development: Development of a Pioneering Program in a Chinese Context. Freund, London.

4. $\quad$ Catalano, R.F., Berglund, M.L., Ryan, J.A.M., Lonczak, H.S., and Hawkins, J.D. (1998) Positive Youth Development in the United States: Research Findings on Evaluations of Positive Youth Development Programs. Available from: http://aspe.hhs.gov/hsp/PositiveYouthDev99/

5. Shek, D.T.L. and Sun, R.C.F. (2006) Implementation of the Tier 1 Program of the Project P.A.T.H.S.: interim evaluation findings. TheScientificWorldJOURNAL 6, 2274-2284.DOI 10.1100/tsw.2006.356.

6. $\quad$ Shek, D.T.L., Ma, H.K., and Sun, R.C.F. (2008) Interim evaluation of the Tier 1 Program (Secondary 1 Curriculum) of the Project P.A.T.H.S.: first year of the full implementation phase. TheScientificWorldJOURNAL: TSW Holistic Health \& Medicine 8, 47-60. DOI 10.1100/tsw.2008.5.

7. Shek, D.T.L. (2006) Effectiveness of the Tier 1 Program of the Project P.A.T.H.S.: preliminary objective and subjective outcome evaluation findings. TheScientificWorldJOURNAL 6, 1466-1474. DOI 10.1100/tsw.2006.238.

8. Shek, D.T.L., Siu, A.M.H., Lee, T.Y., Cheung, C.K., and Chung, R. (2008) Effectiveness of the Tier 1 Program of Project P.A.T.H.S.: objective outcome evaluation based on a randomized group trial. TheScientificWorldJOURNAL: TSW Holistic Health \& Medicine 8, 4-12. DOI 10.1100/tsw.2008.16.

9. Shek, D.T.L. and Ma, H.K. (2007) Subjective outcome evaluation of the Project P.A.T.H.S.: findings based on the perspective of the program participants. TheScientificWorldJOURNAL 7, 47-55. DOI 10.1100/tsw.2007.38.

10. Shek, D.T.L., Siu, A.M.H., and Lee, T.Y. (2007) Subjective outcome evaluation of the Project P.A.T.H.S.: findings based on the perspective of the program implementers. TheScientificWorldJOURNAL 7, 195-203. DOI 10.1100/tsw.2007.43.

11. Shek, D.T.L. and Sun, R.C.F. (2007) Subjective outcome evaluation of the Project P.A.T.H.S.: qualitative findings based on the experiences of program implementers. TheScientificWorldJOURNAL 7, 1024-1035. DOI 10.1100/tsw.2007.161.

12. Shek, D.T.L. and Sun, R.C.F. (2007) Subjective outcome evaluation of the Project P.A.T.H.S.: qualitative findings based on the experiences of program participants. TheScientificWorldJOURNAL 7, 686-697. DOI 10.1100/tsw.2007.126.

13. Shek, D.T.L. (2008) Evaluation of the Tier 1 Program of Project P.A.T.H.S.: secondary data analyses of conclusions drawn by the program implementers. TheScientificWorldJOURNAL: TSW Holistic Health \& Medicine 8, 22-34. DOI 10.1100/tsw.2008.6.

14. Shek, D.T.L., Lee, T.Y., Siu, A., and Lam, C.M. (2006) Qualitative evaluation of the Project P.A.T.H.S. based on the perceptions of the program participants. TheScientificWorldJOURNAL. 6, 2254-2263. DOI 10.1100/tsw.2006.354.

15. Shek, D.T.L., Sun, R.C.F., Lam, C.M., Lung, D.W.M., and Lo, S.C. (2008) Evaluation of positive youth development in Hong Kong: utilization of student weekly diary. TheScientificWorldJOURNAL: TSW Holistic Health \& Medicine 
8, 13-21. DOI 10.1100/tsw.2008.2.

16. Shek, D.T.L., Ma, H.K., Lui, J.H.Y., and Lung, D.W.M. (2006) Process evaluation of the Tier 1 Program of the Project P.A.T.H.S. TheScientificWorldJOURNAL. 6, 2264-2273. DOI 10.1100/tsw.2006.355.

17. Shek, D.T.L., Ma, H.K., Sun, R.C.F., and Lung, D.W.M. (2008) Process evaluation of the Tier 1 Program (Secondary 1 Curriculum) of the Project P.A.T.H.S.: findings based on the full implementation phase. TheScientificWorldJOURNAL. 8, 35-46. DOI 10.1100/tsw.2008.4.

18. Shek, D.T.L., Ma, H.K., Sun, R.C.F., Yu, F.S.Y., Choi, E.M.L., Choy, S., and Chow, J.T.W. (2007) Users’ manual. In P.A.T.H.S. to Adulthood: A Jockey Club Youth Enhancement Scheme. Secondary Two Curriculum. Users’ Manual and Activity Handbook 1. 2nd ed. Shek, D.T.L., Ma, H.K., Lee, T.Y., Lau, P.S.Y., Tsang, S.K.M., and Sun, R.C.F., Eds. Social Welfare Practice and Research Centre, Department of Social Work, The Chinese University of Hong Kong, Hong Kong.

19. Scheirer, M.A. (1994) Designing and using process evaluation. In Handbook of Practical Program Evaluation. Wholey, J.S., Hatry, H.P., and Newcomer, K.E., Eds. Jossey-Bass, San Francisco. pp. 40-68.

20. Linnan, L. and Steckler, A. (2002) Process evaluation for public health interventions and research: an overview. In Process Evaluation for Public Health Interventions and Research. Steckler, A. and Linnan, L., Eds. Jossey-Bass, San Francisco. pp. 1-23.

21. Weinbach, R.W. (2005) Evaluating Social Work Services and Programs. Allyn and Bacon, Boston.

22. Meyer, A., Miller, S., and Herman, M. (1993) Balancing the priorities of evaluation with the priorities of the setting: a focus on positive youth development programs in school settings. J. Primary Prev. 14(2), 95-113.

23. Shek, D.T.L., Tang, V., and Han, X.Y. (2005) Quality of qualitative evaluation studies in the social work literature: evidence that constitutes a wakeup call. Res. Soc. Work Pract. 15, 180-194.

24. Miles, M.B. and Huberman, A.M. (1994) Qualitative Data Analysis. Sage, Thousand Oaks, CA.

25. Shek, D.T.L., Lee, T.Y., and Sun, R.C.F. (2008) Process Evaluation of the Implementation of the Secondary 2 Program of Project P.A.T.H.S. in the Experimental Implementation Phase. TheScientificWorldJOURNAL: TSW Holistic Health \& Medicine. 8, 83-94. DOI 10.1100/tsw.2008.23.

26. Ho, I.T. (2001) Are Chinese teachers authoritarian? In Teaching the Chinese Learner: Psychological and Pedagogical Perspectives. Watkins, D.A. and Biggs, J.B., Eds. Comparative Education Research Centre, The University of Hong Kong, Hong Kong. pp. 99-114.

27. Singleton, R.A. and Straits, B.C. (2005) Approaches to Social Research. Oxford University Press, New York.

\section{This article should be cited as follows:}

Shek, D.T.L., Sun, R.C.F., and Siu, A.M.H. (2008) Interim evaluation of the Secondary 2 Program of Project P.A.T.H.S.: insights based on the experimental implementation phase. TheScientificWorldJOURNAL: TSW Holistic Health \& Medicine 8, 61-72. DOI 10.1100/tsw.2008.22. 